\title{
Holes' Parameters Analysis of a Perforated Thin-Walled Lipped Beam Buckled Under a Bending Load
}

\author{
D.S. Khazaal, Hussein M. H. Al-Khafaji and I.A. Abdulsahib \\ Department of Mechanical Engineering, University of Technology, Baghdad, Iraq
}

\begin{abstract}
This work studied the effects of holes on the buckling characteristic of an open thinwalled lipped channel beam under a bending load. A nonlinear finite element method was utilised to examine the buckling behaviour of the beam. Experimental works were carried out to verify the finite element simulation. Three factors were chosen to examine their influence on the buckling of the beam. These factors namely, the holes' shape, perforated ratio (hole length to beam height) and spacing ratio (centre to centre distance between holes to beam height). The finite elements output was analysed by implementing the Taguchi method to distinguish the best group of three parameters collections for optimal strength of buckling. Whereas the analysis of variance technique (ANOVA) method was applied to specify the impact of each parameter on critical buckling load. Outcomes showed that the combination of parameters that gives the best buckling strength is the hole with a hexagonal shape, perforated ratio $=1.7$ and spacing ratio $=1.3$, and the holes' shape is the most effective factor. In addition, the study demonstrated that the hole's shape factor has the greatest influence on the buckling capacity. While the perforated ratio factor is the least influential.
\end{abstract}

ARTICLE HISTORY

Received: $13^{\text {th }}$ Nov 2020

Revised: $21^{\text {st }}$ Aug 2021

Accepted: $5^{\text {th }}$ Sept 2021

\section{KEYWORDS}

Thin-Walled structure;

Buckling bending of perforation lipped beam; Nonlinear finite elements; Taguchi method; ANOVA method

\section{INTRODUCTION}

Thin-walled open section beams are extremely used in engineering applications because of their favourable strength/weight ratio, simplicity of erection and installation, ease of fabrication, and economic conditions. This type of structure is exposed during service to different physical phenomena; one is the buckling which is a consequence of several types of loading. The buckling manner is affected by different variables like the geometry of the cross-section, boundary condition (supports and loads), material properties, and dimensions of the structure. [1].

An open-lipped channel beams are one of the most common sections. Numerous scholars investigated the behaviour of thin-walled beams; most of them used I, C, or Z sections in their investigations as these are widely used sections in structures. White et al. [2] examined the maximum strength experimentally and theoretically of two series of the closedhat square thin-walled beam with different thicknesses affected by the combined loads bending and torsion. Linear-elastic and rigid-plastic approaches were implemented to find interaction equations to estimate the load resistance of the section for any combined load (bending - torsional). Javaroni and Goncalves [3] compared experimental results with the direct strength method to investigate the distortional buckling of lipped beams. These beams were exposed to bending loading. The study indicated that the strength of regional and distortional buckling from the two methods are very similar. Zhang and Tong [4] contrasted the flexural-torsional buckling behaviour of thin-walled beams using three theories. One of these theories was proposed by the author, whereas the others are traditional; according to these theories, the finite element programs were developed. The proposed solution demonstrates a good agreement with the other theories in some cases and has an advantage over existing theories represented by simplicity.

Ye et al. [5] carried out an experimental study to interact with local and flexural buckling mode for cold-formed steel columns subjected to an axial compressive load. The experimental outcomes were verified by the Eurocode 3 design procedures. The experiments succeeded in realising the interaction between flexural buckling and local buckling. Kolakowski and Jankowski [6] investigated analytically the influence of beam length on the load-carrying capacity for the steel-lipped beams affected by bending load. They found that the effect of the second global mode on the load capacity is most clear for moderate beams. Grenda and Paczos [7] studied experimentally and numerically the local stability of thin-walled channel beams with uncommon flanges made of cold-rolled steel sheets subjected to pure bending. The finite strip and finite element methods were used in the numerical analysis. The difference between numerical results and experimental was small, less than $2 \%$. The results affirmed that the local buckling restricts the load capacity of the beam. Moen and Shafer [8] examined the modified Direct Strength Method that was applied to perforated structures. Moreover, it estimated the effect of a slotted on the buckling behaviour of a flat plate and cold-form steel structure. A parametric study was carried out based on the dimensions of the hole. The finite element method was used for simulation. The elastic buckling was analysed by applying the Eigen buckling analysis utilising the finite element software ABAQUS. In addition, they expanded their works to test experimentally and numerically the short and intermediate columns under a compression load [9]. These studies proved that the holes make the column rely on the flanges to carry on a load under distortional failure. Macdonald and Kulatunga et al. [10]-[13] investigated experimentally and numerically the effects of 
perforations' shape and their positions as well as the boundary conditions of end on the compressive load capacity of perforated steel columns with a lipped channel. The outcomes showed that; the ultimate buckling load of the structure subjected to compression changed highly with the hole distribution pattern. There is a higher lowering of stiffness related to circular holes than slotted holes of the same cross-section area. Grilo et al. [14] suggested a new formulation to find the resistance of shear for Web-post buckling of steel cellular beams.

A parametric analysis was carried out using a developed numerical model in ABAQUS. This model was verified experimentally. Based on the numerical model, many cases were done to estimate the new formulation of shear resistance calculation for the cellular beams. Ferreira and Martins [15] investigated the torsional- lateral buckling strength in cellular beams under three kinds of loading; bending, uniformly distributed load, and mid-span concentrated load. Material and geometric nonlinear analyses were used to simulate the buckling behaviour of the beams, and the results were checked with the standard of ANSI/AISC 360-16. The comparison showed that the American calculation procedure is ineffective under inelastic buckling behaviour. Degtyareva et al.[16] researched the effects of using staggered slotted holes on the local buckling behaviour of cold-formed steel beams. Three-dimensional finite element models were employed for parametric analysis, which was exercised to estimate the ultimate bending load capacity of beams subjected to the local buckling.

Studying parameters is very important for obtaining the best condition for maximum or minimum. Amongst different methods, the Taguchi and analyses of variance (ANOVA) techniques are efficient for optimisation, finding the best and most influential parameters. Several scholars discussed these two methods in buckling studies [17] to [22]. In this work, numerical and experimental investigations were presented to examine the buckling behaviour of perforated thin-walled lipped channel cantilever beams subjected to bending load, and the material of beams is aluminium alloy 6061-0. Three factors were selected to evaluate their effect on the buckling behaviour of the beam. These parameters are shapes' hole, hole length to beam height ratio (perforated ratio), and centre to centre distance between holes to beam height ratio (spacing ratio). The Taguchi method was used to specify the better set of three factors combinations for the best critical buckling load. Furthermore, the (ANOVA) was employed to find the most effective factor on the critical load of buckling.

\section{THEORY}

\section{Buckling and Finite Element}

Buckling is a state of a structure in which the applied loads are large enough to disturb or destroy its stability. The linear buckling analysis determines the theoretical strength of buckling. It is modelled as an eigenvalue equation:

$$
\left(k+\lambda k_{\sigma}\right) \psi=0
$$

where, $k_{\sigma}$ is a stress-stiffness matrix, $\lambda$ is the eigenvalue (load factor), $k$ is a stiffness matrix, and $\psi$ is the eigenvector of displacements. The solutions for this formula are the eigenvalues and corresponding eigenvectors. The smallest value from the eigenvalues represents the critical load factor of buckling. If the applied load is $F$, then the critical load will be $\left(\lambda^{*} F\right)$. If the load is pure bending, and the cross-section of the structure is symmetric, there will be positive and negative load factors, but they have equal absolute values. Therefore, it must take the critical load factor according to the direction of the applied load [23] and [24].

\section{Nonlinear Buckling Analysis}

Nonlinear buckling analysis gives a greater accuracy than elastic formulation. This analysis is a static method, which concerns a nonlinearity of materials and geometrics, and boundaries' nonlinearity. In this type of analysis, the load is applied gradually until a small increment of the load makes a big change in displacement; at this point, the state of the structure becomes unstable, and the load represents the critical buckling load [25]. This study used the nonlinear analysis because it is close to the real behaviour of the structure.

\section{Taguchi}

Genichi Taguchi founded the Taguchi method in 1949. It is a methodology for acquiring the relationship between the input process and output of products. It depends on using an orthogonal array (OA) with a few tests to get the most favourable set of parameters for the process. This method is a good tool for better design, gathering the concept of the quality loss function and design of experiment theory. It provides a systematic approach for optimising design performance, cost, and quality. Moreover, the method employs a statistical measurement named the ratio of the mean (called signal) to the standard deviation (called noise) $(\mathrm{S} / \mathrm{N})$, which represents a logarithmic function of the wanted output. There are three standard types of S/N ratio; higher the best (HB), lower the best (LB) and nominal the better (NB) [19], [21] and [26]. In this study, the higher buckling strength is required; therefore, the higher, the better formula is used:

$$
S / N=-10 \log \left(\frac{1}{n} \sum_{i=1}^{n} \frac{1}{y^{2}}\right)
$$

where, $y$ represents the read data, and $n$ is the observations' number. 


\section{Analysis of Variance (ANOVA)}

Analysis of variance (ANOVA) is an efficient statistical technique, which specifies the important parameters and demonstrates the percentage contribution of each parameter. In this research, the ratio $(\mathrm{S} / \mathrm{N})$ was used for making the decision. The technique of ANOVA is based on the total sum of squared deviations (SST) which is equal to [27] :

$$
S S_{T}=\sum_{i=1}^{n}\left(n_{i}-n_{m}\right)^{2}
$$

The percentage of contribution $P$ could be calculated as:

$$
\begin{gathered}
P=\frac{S S_{d}}{S S_{T}} \\
\text { d.o.f of any parameter }(\text { factor })=k-1 \\
\text { Total d.o.f }=n-1 \\
\text { d.o.f of error = total d.o.f }-\sum \text { d.o.f of parameters } \\
V=\frac{S S_{d}}{d . o . f} \\
F=\frac{V}{V_{E}}
\end{gathered}
$$

where, $n$ is the number of trails (observation) in the orthogonal array, $n_{i}$ is mean of $\mathrm{S} / \mathrm{N}$ ratio for the ith observation, $n_{m}$ is mean of all parameters, $S S_{d}$ is a summation of the squared deviations, $K$ is levels' number for each parameter, $P$ is contribution's percentage, $V$ is parameter's (factor) variance, $V_{E}$ is error's variance, $d . o . f$ is the degree of freedom, and $F$ is $F$ - test, which is an indicator of the quality characteristic of the process.

\section{EXPERIMENTAL PROGRAM}

\section{Material Properties}

Aluminium alloy 6061-0 sheets with $1.6 \mathrm{~mm}$ thickness were used to manufacture the specimens. Tensile tests were performed to validate the mechanical properties of sheets. Tests were done on the tensile specimens with dimensions according to ASTM specifications B557M-02a [28], as indicated in Figure 1. Table 1 lists the test results from an average of three specimens.

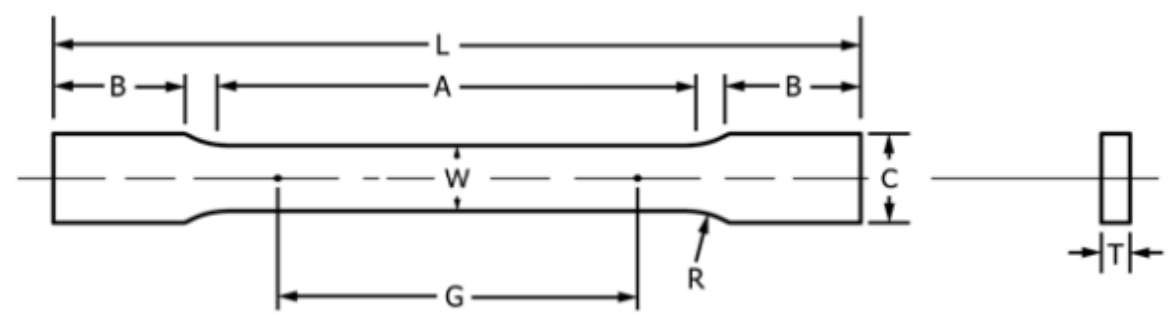

All dimensions in $\mathrm{mm}$

$\mathrm{G}$ : Gage length 57

W: Width

T: Thickness

1.6

R: Radius of fillet

12.5

A: Length of reduced section

60

L: Overall length

180

B: Length of the grip section

50

C: Width of the grip section

20

Figure 1. Tensile test specimens. 
Table 1. Properties of aluminium alloy 6061-0

\begin{tabular}{lc}
\hline Aluminium alloy $6061-0$ & Experimental measured \\
\hline Young modulus, E (Gpa) & 68.9 \\
Poisson's ratio, 0 & 0.33 \\
Yield stress, $\sigma_{\mathrm{y}}(\mathrm{Mpa})$ & 70 \\
Ultimate stress, $\sigma_{\mathrm{u}}(\mathrm{Mpa})$ & 109 \\
\hline
\end{tabular}

\section{Specimen Geometry}

The cross-section dimensions were designed according to the design constraints of Eurocode (EN-1993-1-3) [29], as shown in Figure 2. The beam length is assumed to be $500 \mathrm{~mm}$ for all specimens. The design constraints of the lipped channel beam are given as follows.

$$
\begin{gathered}
\frac{b}{t} \leq 60, \quad \frac{a}{t} \leq 50, \quad h / t \leq 500 \\
0.2 \leq a / b \leq 0.6 \\
a \leq 25
\end{gathered}
$$

where $t$ represents the thickness, $h$ is the cross-section's depth, and $b$ is the width of the flange and $a$ is the width of the lip.

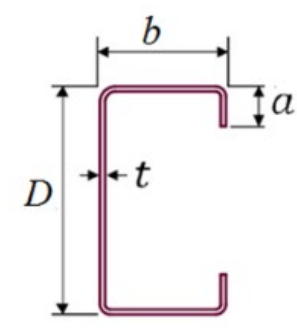

Cross-section

\begin{tabular}{|cc}
\hline$D(\mathrm{~mm})$ & 100 \\
$b(\mathrm{~mm})$ & 38 \\
$a(\mathrm{~mm})$ & 12 \\
$t(\mathrm{~mm})$ & 1.6 \\
\hline
\end{tabular}

Figure 2. Specimen cross-section dimensions.

Three shapes of holes were chosen to be made in the web, as demonstrated in Figure 3, with dimensions according to the recommendations for web openings into cellular beams provided by Eurocode (BS-5950) [30]:

$$
1.25<D / D \_O<1.75
$$

$$
1.08<S / D_{O}<1.5
$$
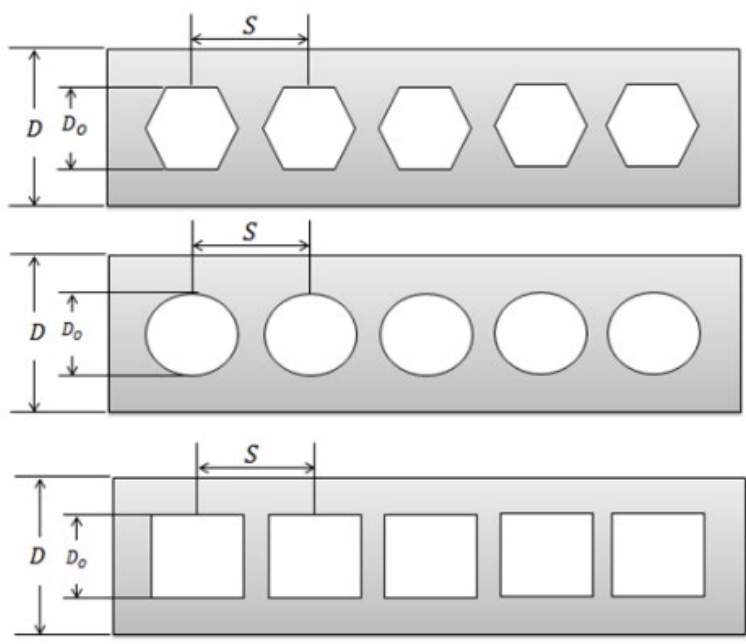

Figure 3. Types of holes shapes.

Table 2 shows the chosen parameters in three levels for analysis: holes' shape $(\mathrm{SH})$, perforated ratio $\left(D / D_{o}\right)$ and spacing ratio $\left[S / D_{o}\right]$. Four specimens were tested in this work to verify the numerical solution. One of them is without holes as a reference beam (RB), and others have five holes with common shapes of (hexagonal, circular and square), as shown in Figure 4. The cross-section of lipped beams was made by flexing the Aluminium alloy 6061-0 sheet. The water 
jet process was used to make holes on the web of the beam to get a good surface finishing and to minimise any residual stresses at the area of the holes. Two cubes from Teflon were mounted at the two ends of the beam to prevent any local distortion of a cross-section. The dimensions are $96.5 \times 34.5 \times 20 \mathrm{~mm}$ at the load application and $96.5 \times 34.5 \times 50 \mathrm{~mm}$ at the fixed end. The specimens were fixed using a fixture stand, as indicated in Figure 5.

Table 2. Parameters and levels.

\begin{tabular}{lcccc}
\hline \multirow{2}{*}{ Symbols } & \multirow{2}{*}{ Parameters } & \multicolumn{3}{c}{ Levels } \\
\cline { 3 - 5 } & & Level 1 & Level 2 & Level 3 \\
\hline $\mathrm{A}$ & Shape of holes & Hexagonal & Circular & Square \\
$\mathrm{B}$ & $D / D_{o}$ & 1.7 & 1.6 & 1.5 \\
$\mathrm{C}$ & $S / D_{o}$ & 1.5 & 1.4 & 1.3 \\
\hline
\end{tabular}
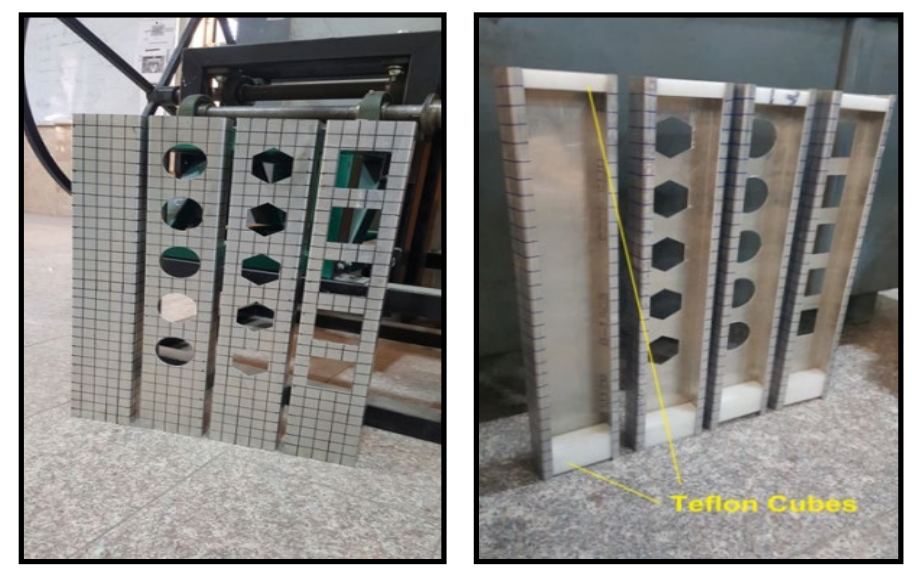

(a)
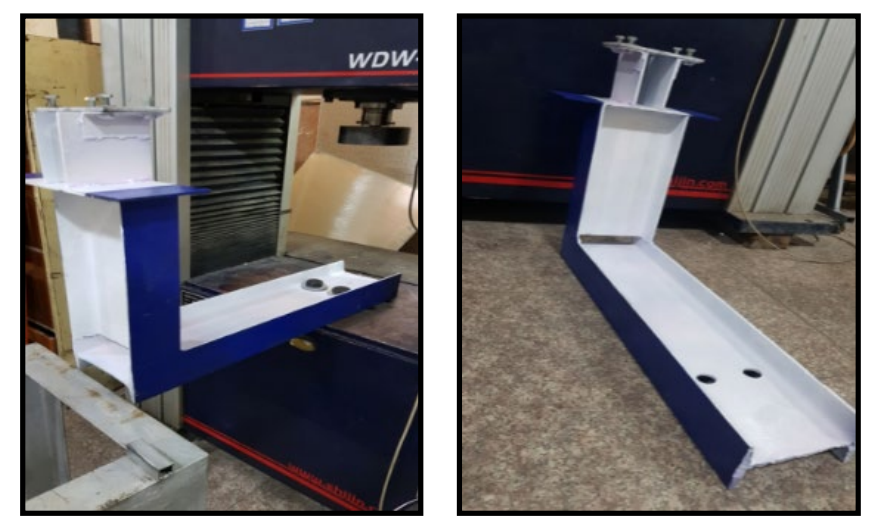

(b)

Figure 4. (a) Test specimens, and (b) fixture stand.

\section{Buckling Test}

The computer-controlled electronic universal testing machine type WDW-200E was used for the bending buckling test, as shown in Figure 6. Four specimens of thin-walled lipped channel beams were tested as cantilever beams under a bending load. The bending load was applied at the free end gradually with the rate of $3 \mathrm{~mm} / \mathrm{min}$, as indicated in Figure 7. The load-displacement curves for the tested beams were recorded by the controlling computer.

\section{FINITE ELEMENT ANALYSIS}

\section{Modelling}

The perforated beams were modelled and analysed using ANSYS 15 software. SHELL181- element was utilised for meshing model, which is suitable for thin structure. It is featured with four nodes having three degrees of freedom for translations and three for rotations. Moreover, SHELL181 is fit with linear, large strain nonlinear and large rotation applications [31]. Figure 8 shows the finite element model of the cantilever beams with the three shapes of holes. The force $\mathrm{F}$ is applied in the downward direction on the top edge at the free end. To prevent flange deformation at where the load was acting, a solid cube of size $(96.5 \times 34.5 \times 20)$ was added between the upper and lower flanges, as in Figure 9 . The cube and the beam are assumed made from the same material. 


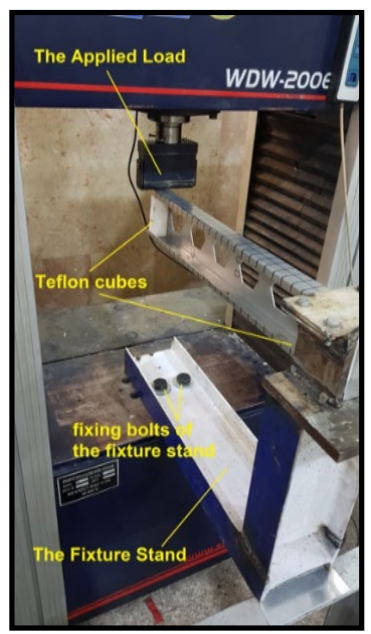

(a)
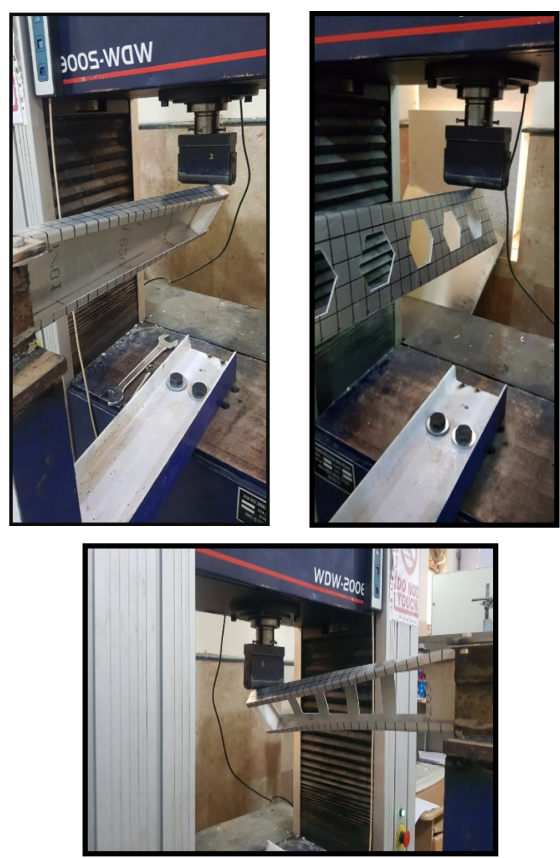

(b)

Figure 5. (a) Arrangement of the buckling test, and (b) buckling test.
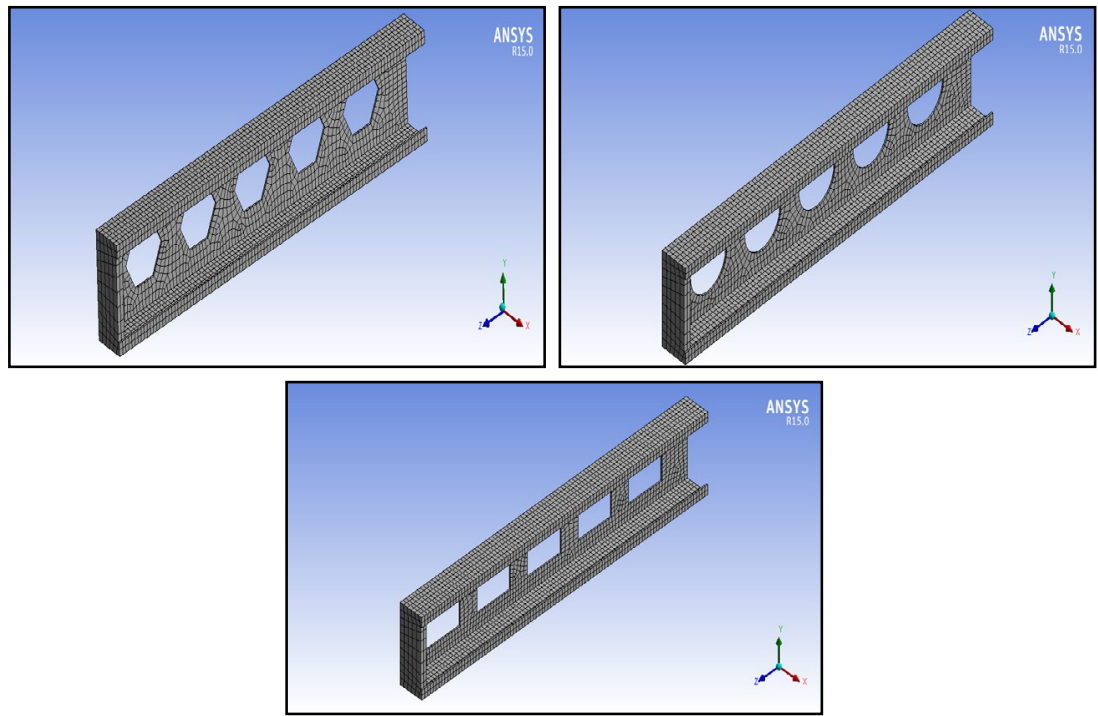

Figure 6. Models of the beam.

\section{Convergence Study}

The mesh convergence was established by increasing the mesh density in each part of the model and comparing the variation in the buckling load. Different dimensions of elements were tested. The elements dimensions between 10 and 5 $\mathrm{mm}$ showed no significant differences in load, whereas the processing time was considerable. Any increment in mesh density was unnecessary, as highlighted in Figure 10. Therefore, an element size of $10 \mathrm{~mm}$ (3322 elements) was used in subsequent analyses.

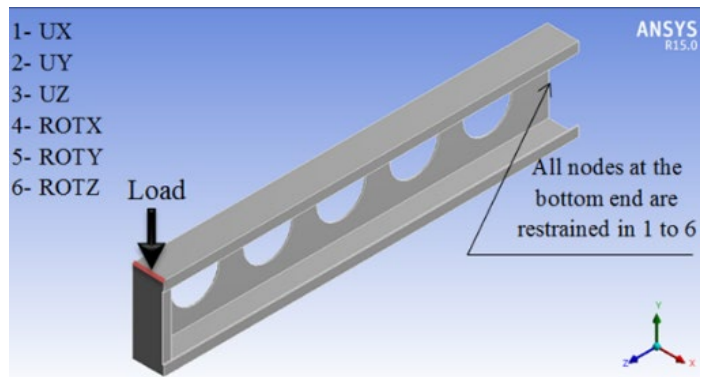

Figure 7. Load and boundary conditions. 


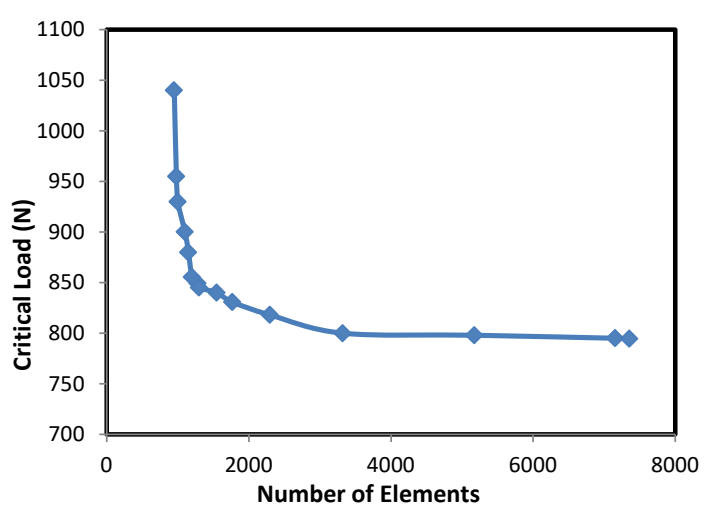

Figure 8. Critical load vs number of elements (mesh density).

\section{RESULTS AND DISCUSSION}

Experimental tests revealed that the beams (with and without holes) deformed under the lateral-torsional buckling mode (LTB), as displayed in Figure 11. Figure 12 demonstrates the load-displacement curves resulted from the experimental test, and the results of the critical buckling load were listed in Table 3. The experimental results showed that the buckling strength of the thin-walled beam decreases with the presence of holes on the web when subjected to bending load.

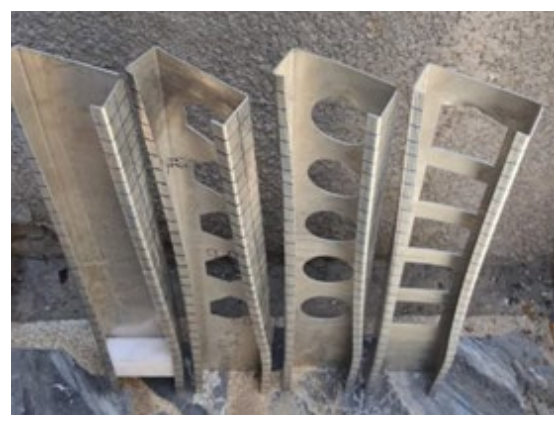

Figure 9. Deformed specimens.

Table 3. Experimental results.

\begin{tabular}{lccc}
\hline Shape of holes & $D / D_{0}$ & $S / D_{0}$ & $P_{E X P}(\mathrm{~N})$ \\
\hline Without holes (Ref.) & ---- & ---- & 710 \\
Hexagonal & 1.7 & 1.5 & 590 \\
Circular & 1.7 & 1.5 & 560 \\
Square & 1.7 & 1.5 & 520 \\
\hline
\end{tabular}

\section{Finite Elements Analysis}

The ANSYS analysis and the experimental results gave good compatibility. Table 4, Figure 12 and Figure 13 show the comparison between the experimental and numerical results for the buckling. Figure 14 proves the similarity between the buckling behaviours of experimental and numerical simulation, as well as indicates that the LTB is the mode of failure for the perforated beams. The hexagonal beam has a higher strength than the other shapes. The superiority of the hexagonal shape over the other might be attributed to the mechanism of LTB failure. The mechanism of LTB states that if the reference beam is under a bending load, the load will be resisted by the compression flange and tension flange. The compression flange tends to be displaced laterally away from its axis and to undergo rotation.

Table 4. Experimental and FEM critical loads.

\begin{tabular}{lccccc}
\hline Shape of holes & $D / D_{o}$ & $S / D_{o}$ & $P_{\mathrm{FEM}}(\mathrm{N})$ & $P_{\text {EXP }}(\mathrm{N})$ & $\mathrm{P}_{\text {EXP }} / \mathrm{P}_{\mathrm{FEM}}$ \\
\hline Without holes & --- & --- & 730 & 710 & 0.97 \\
Hexagonal & 1.7 & 1.5 & 610 & 590 & 0.97 \\
Circular & 1.7 & 1.5 & 589.9 & 560 & 0.95 \\
Square & 1.7 & 1.5 & 529.88 & 520 & 0.98 \\
\hline
\end{tabular}




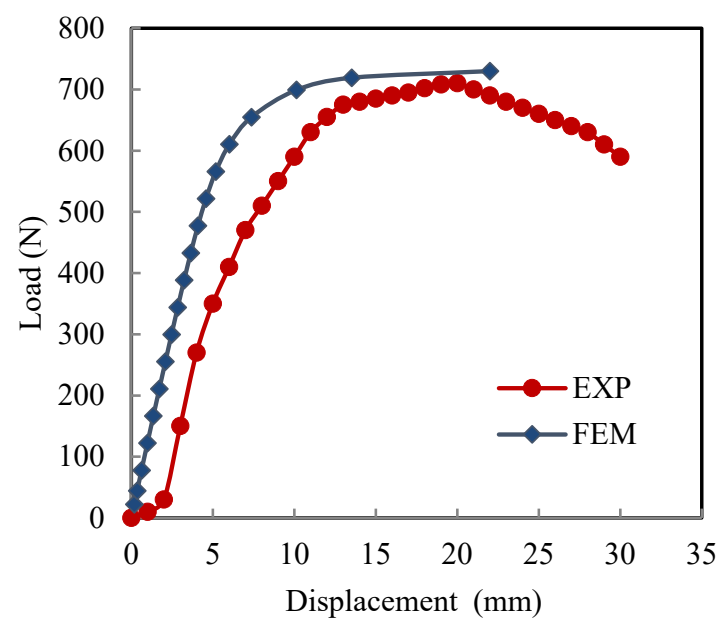

(a) ref beam without hole

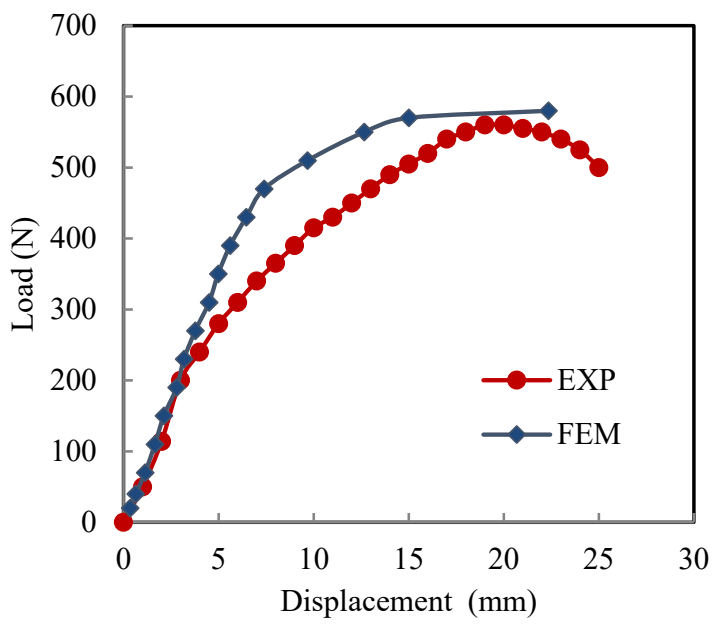

(c) circular holes

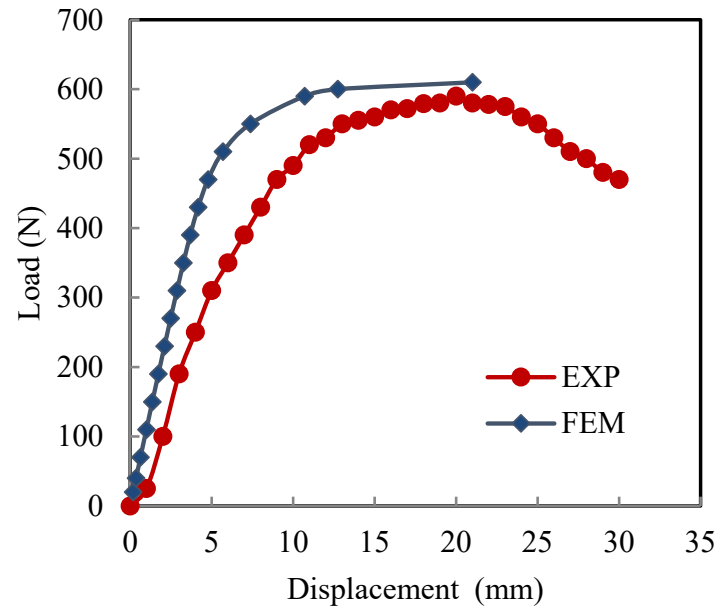

(b) hexagonal holes

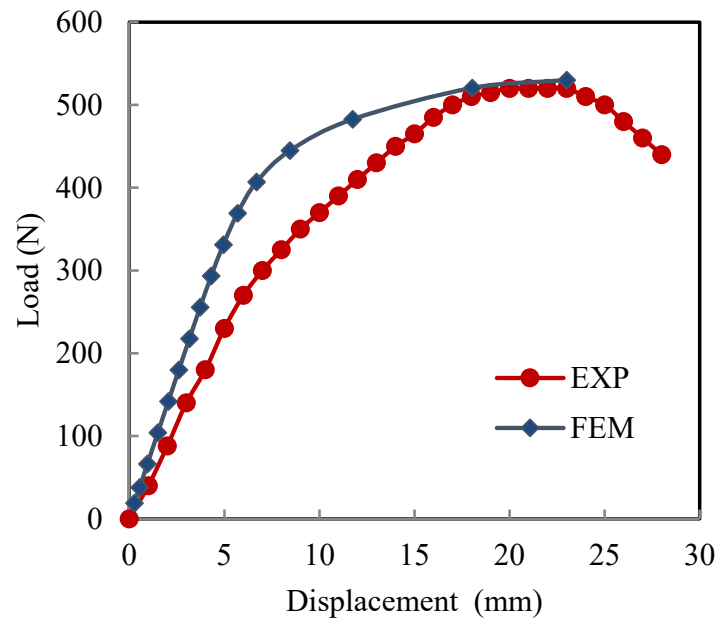

(d) square holes

Figure 10. The experimental vs FEM load-displacement curves of the beams.

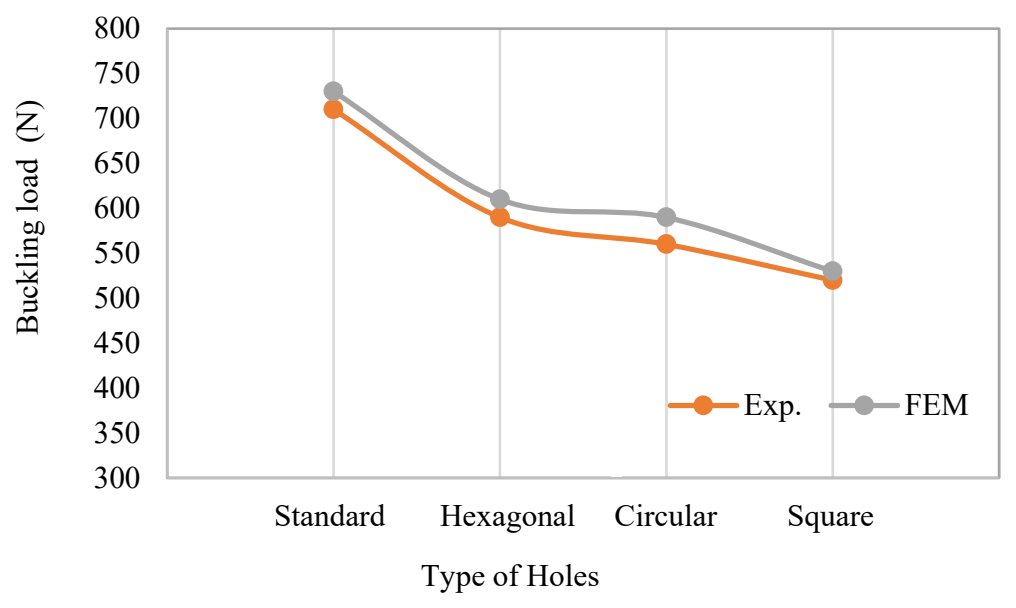

Figure 11. Experimental and numerical critical loads.

Nonlinear buckling finite element analyses were conducted to obtain the value of critical buckling load. Based on the three parameters and three levels, an orthogonal array from 27 combinations (L27) was set up, as indicated in Table 6. For each combination, the critical buckling load value was calculated. Furthermore, the weight of the beam (W) and the strength to weight ratio ( $\mathrm{P} / \mathrm{W})$ are also represented in Table 6. 


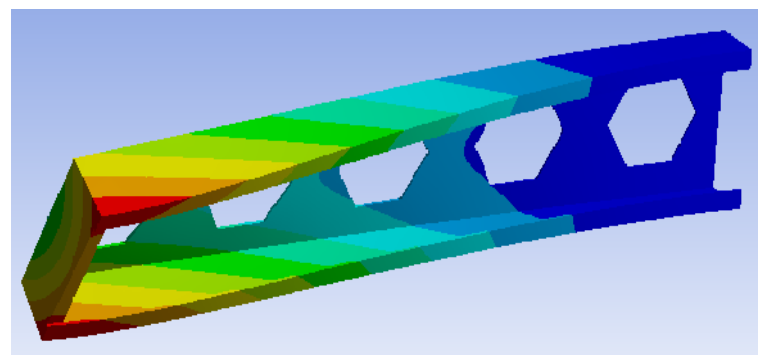

(a) simulation mode for hexagonal hole

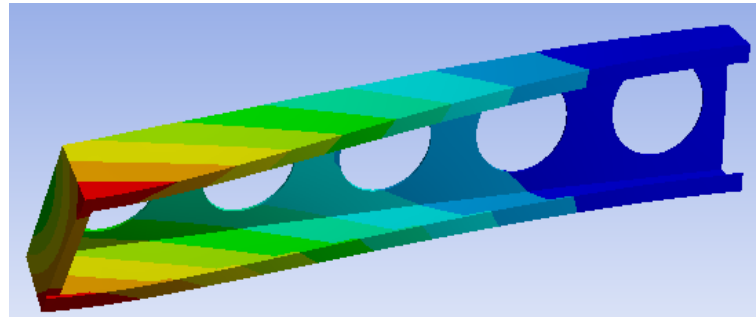

(c) simulation mode for circular hole

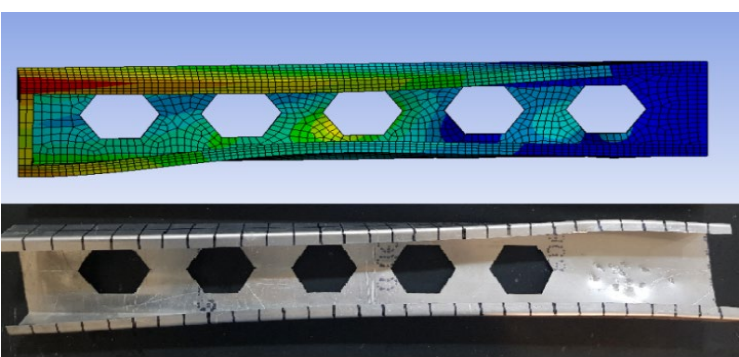

(b) experimental and simulation modes for hexagonal hole.

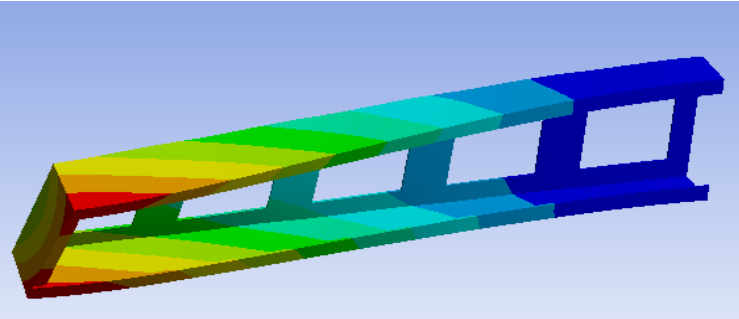

(d) simulation mode for square hole

Figure 12. Experimental and simulation buckling failure in beam.

On the other hand, the tension flange tends to stay at its original position. This difference in the two flanges behaviour causes stresses to be exerted along the beam section. The web transfers these stresses between the flanges by which the tension flange try to restrain the compression flange. This restraint strengths the beam against the lateral buckling torsional effect. For a perforated beam, the vertical web for transferring internal forces will be the solid region (web post) that remains between the holes; whereas, the upper and lower tee regions (along the beam's span) will be the tension and compression members, as shown in Figure 15. Accordingly, the strength of the perforated beam is less than the reference beam. This strength is influenced by the shape and size of holes and the space between them (the distance S ) [32], [14], [33] and [34].
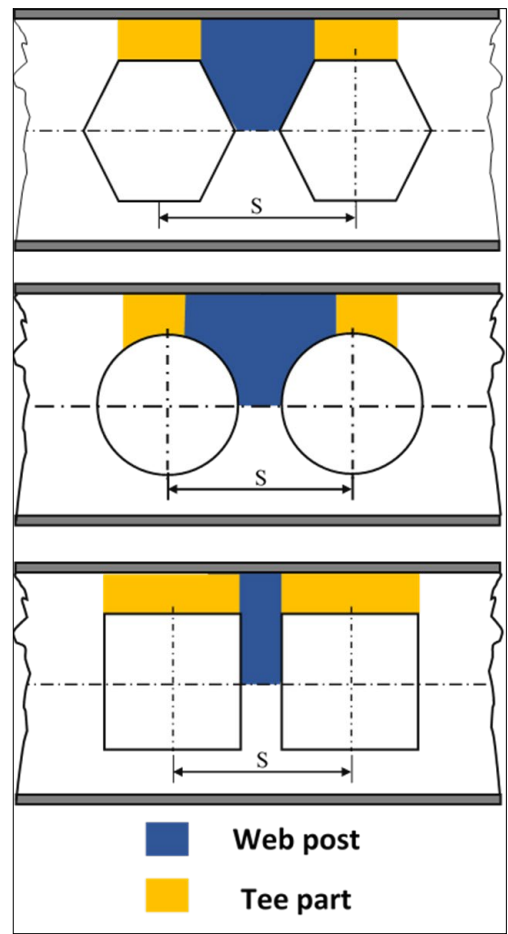

Figure 13. Web regions. 
Table 5. Orthogonal array with the critical load.

\begin{tabular}{lcccccc|ccccccc}
\hline $\begin{array}{l}\text { Test } \\
\text { no. }\end{array}$ & $\begin{array}{c}\text { Holes } \\
\text { shape }\end{array}$ & $D / D_{o}$ & $S / D_{o}$ & $P(\mathrm{~N})$ & $\begin{array}{c}W \\
(\mathrm{~N})\end{array}$ & $P / W$ & $\begin{array}{l}\text { Test } \\
\text { no. }\end{array}$ & $\begin{array}{c}\text { Holes } \\
\text { shape }\end{array}$ & $\begin{array}{c}D \\
/ D_{o}\end{array}$ & $S / D_{o}$ & $P(\mathrm{~N})$ & $\begin{array}{c}W \\
(\mathrm{~N})\end{array}$ & $P / W$ \\
\hline 1 & Hex. & 1.7 & 1.5 & 610 & 3.63 & 168.2 & 15 & Sq. & 1.6 & 1.4 & 530 & 3.27 & 161.9 \\
2 & Cir. & 1.7 & 1.5 & 589.9 & 3.53 & 167.3 & 16 & Hex. & 1.5 & 1.4 & 579.84 & 3.49 & 166.1 \\
3 & Sq. & 1.7 & 1.5 & 529.88 & 3.37 & 157.3 & 17 & Cir. & 1.5 & 1.4 & 548 & 3.36 & 163.0 \\
4 & Hex. & 1.6 & 1.5 & 587.97 & 3.56 & 164.9 & 18 & Sq. & 1.5 & 1.4 & 500 & 3.16 & 158.2 \\
5 & Cir. & 1.6 & 1.5 & 569.96 & 3.46 & 165.0 & 19 & Hex. & 1.7 & 1.3 & 627.66 & 3.63 & 173.1 \\
6 & Sq. & 1.6 & 1.5 & 507.84 & 3.27 & 155.1 & 20 & Cir. & 1.7 & 1.3 & 609.85 & 3.53 & 172.9 \\
7 & Hex. & 1.5 & 1.5 & 559.94 & 3.49 & 160.4 & 21 & Sq. & 1.7 & 1.3 & 569 & 3.37 & 168.9 \\
8 & Cir. & 1.5 & 1.5 & 539.99 & 3.36 & 160.6 & 22 & Hex. & 1.6 & 1.3 & 609.95 & 3.56 & 171.1 \\
9 & Sq. & 1.5 & 1.5 & 470.95 & 3.16 & 149.0 & 23 & Cir. & 1.6 & 1.3 & 590 & 3.46 & 170.8 \\
10 & Hex. & 1.7 & 1.4 & 617.99 & 3.63 & 170.4 & 24 & Sq. & 1.6 & 1.3 & 540.02 & 3.27 & 164.9 \\
11 & Cir. & 1.7 & 1.4 & 599.94 & 3.53 & 170.1 & 25 & Hex. & 1.5 & 1.3 & 587.99 & 3.49 & 168.4 \\
12 & Sq. & 1.7 & 1.4 & 555 & 3.37 & 164.7 & 26 & Cir. & 1.5 & 1.3 & 560 & 3.36 & 166.5 \\
13 & Hex. & 1.6 & 1.4 & 599.74 & 3.56 & 168.2 & 27 & Sq. & 1.5 & 1.3 & 507.95 & 3.16 & 160.7 \\
14 & Cir. & 1.6 & 1.4 & 577.99 & 3.46 & 167.3 & & & & & & & \\
\hline
\end{tabular}

\section{Taguchi and ANOVA}

The effect of one parameter on the response might be changed at different levels of the other parameter due to the interaction between these parameters. To determine whether two parameters interact or not, the interaction graph is used. The interaction graph is a graph between two parameters corresponding to their responses, keeping the other parameters at constant values. Figure 16 to Figure 18 include the graphs for the interaction for parameters based on the results in Table 6. Figure 16 contains three graphs for the interaction between the parameters $S / D_{O}$ and the $D / D_{O}$, each graph corresponds to an invariant value for the holes' shape (SH) factor. The graphs indicate that the effect of $S / D_{O}$ at different levels of $D / D_{O}$ is almost the same (the same behavour).

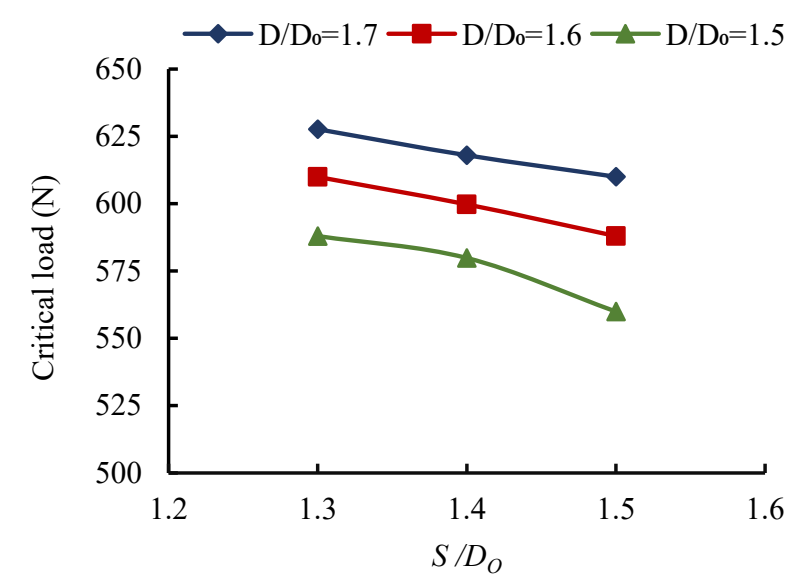

(a) hexagonal shape

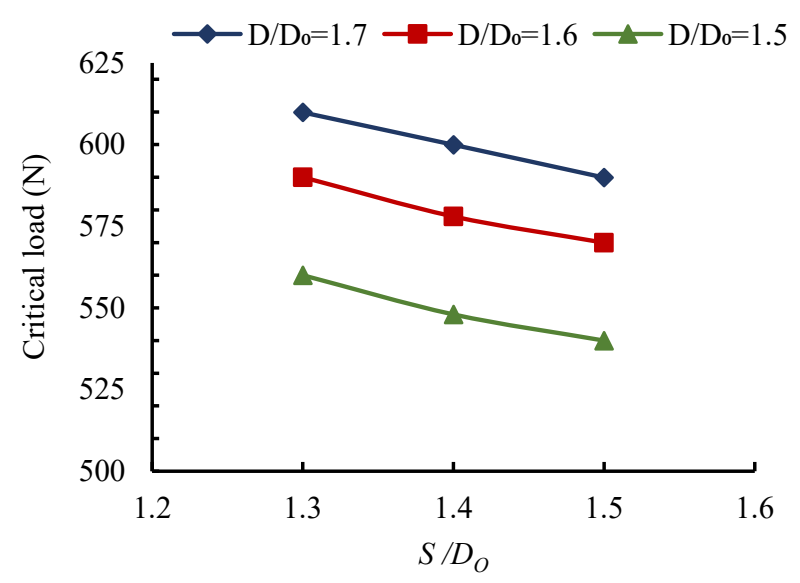

(b) circular shape

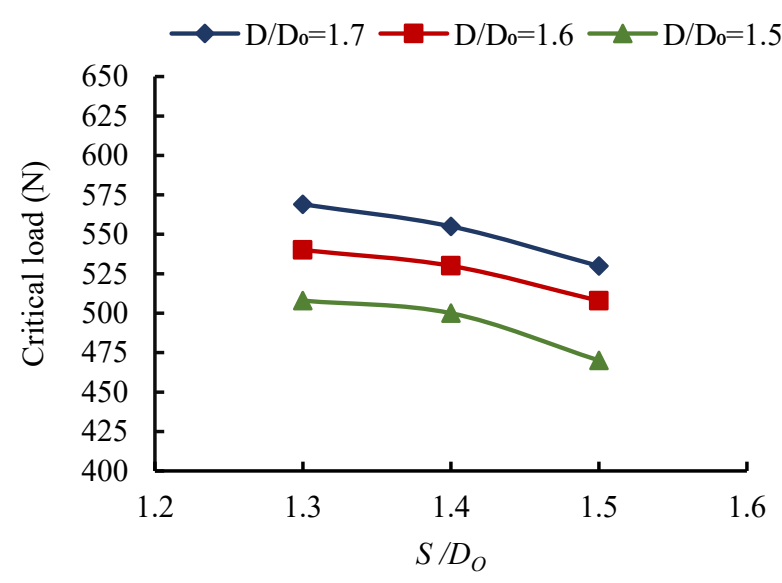

(c) square shape

Figure 14. Interaction graphs between $D / D_{O}$ and $S / D_{O}$ 
Furthermore, the lines are almost parallel, which reveals that there is a little interaction between these two factors. The same is true for the interaction between the $\mathrm{SH}$ and $D / D_{O}$ at each constant value of $S / D_{O}$, as displayed in Figure 17 . Whereas, Figure 18 indicated that there is some kind of interaction between the parameters of the SH and S/Do due to the presence of deviation of the curves from being parallel. Also, it can be seen that the effect of S/D on the critical load at three different levels of SH is not the same, especially in the low level of SH. The outcomes of the finite element analysis were used in Taguchi method calculations. The orthogonal array and values of S/N are listed in Table 7, and the mean based on $\mathrm{S} / \mathrm{N}$ are presented in Table 8 and Figure 19.

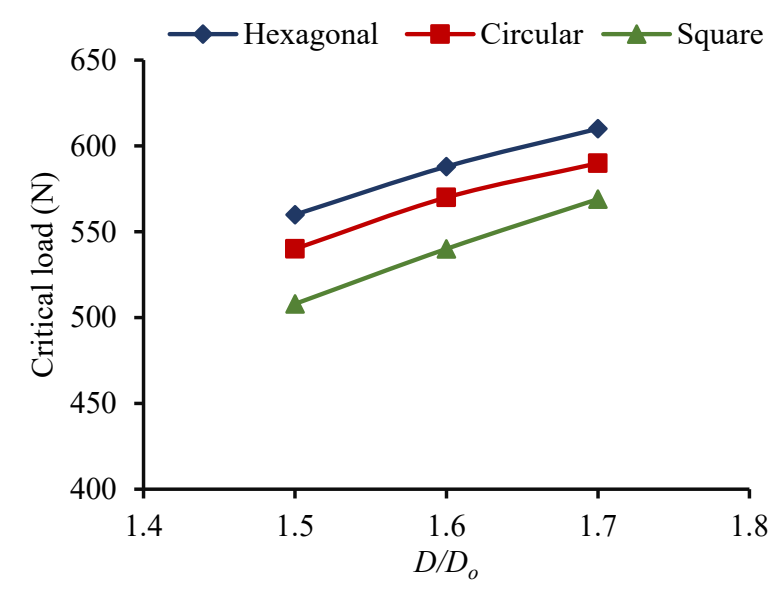

(a) $S / D_{o}=1.5$

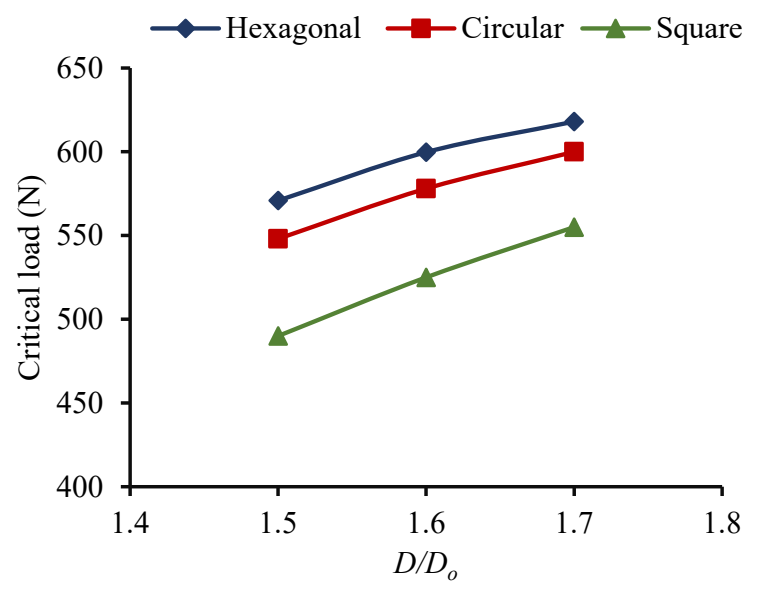

(b) $S / D_{o}=1.4$

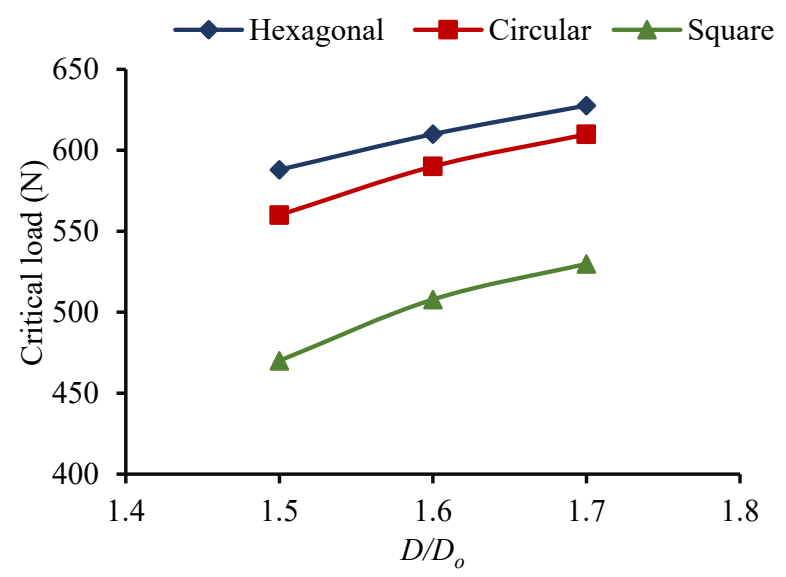

(c) $S / D_{o}=1.3$

Figure 15. Interaction graphs between the $\mathrm{SH}$ and $D / D_{o}$.

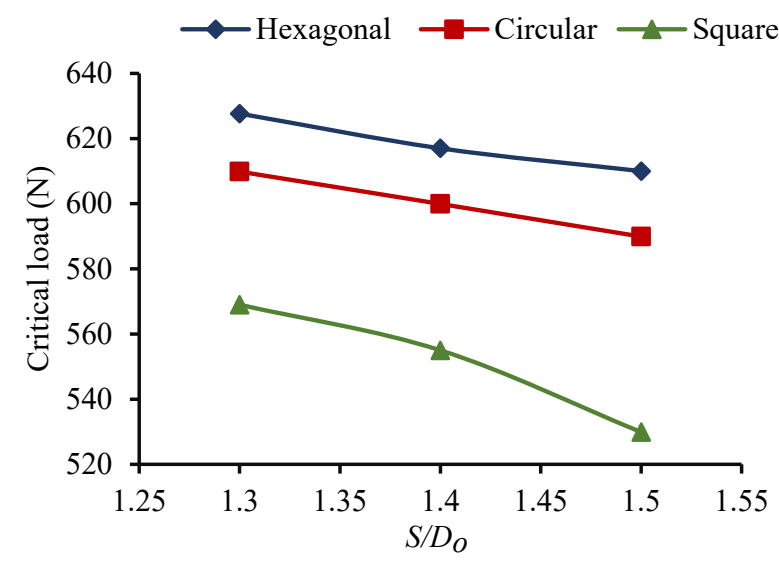

(a) $D / D_{o}=1.7$

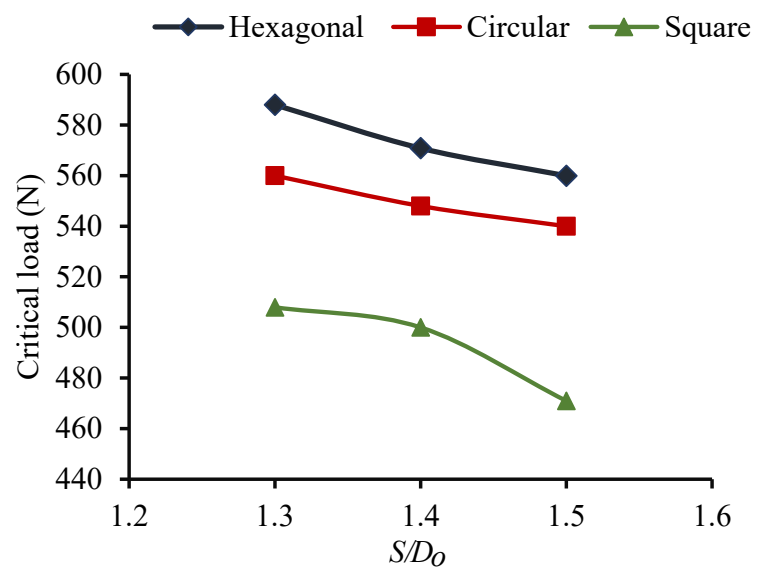

(b) $D / D_{o}=1.5$ 


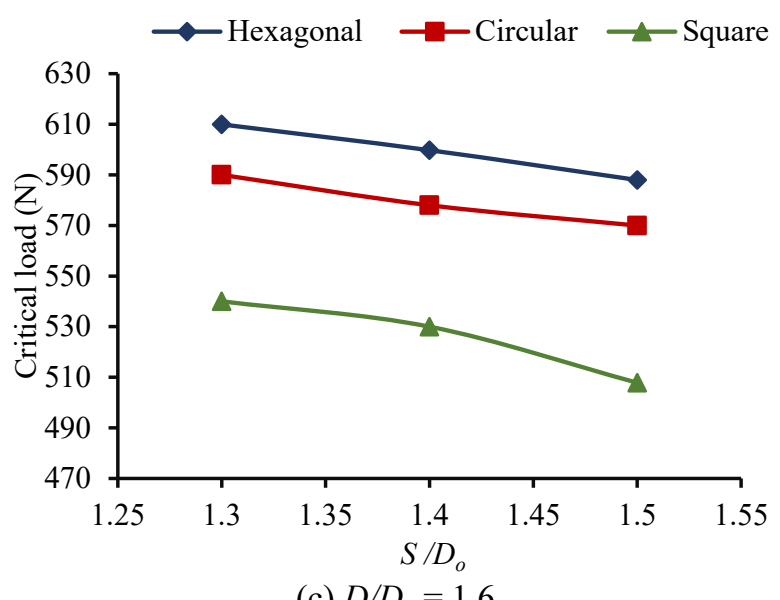

Figure 16. Interaction graphs between the $\mathrm{SH}$ and $S / D_{o}$

Table 6. Orthogonal array and $\mathrm{S} / \mathrm{N}$.

\begin{tabular}{cccccc|lccccc}
\hline $\begin{array}{l}\text { Test } \\
\text { no. }\end{array}$ & $\begin{array}{c}\text { Shape of } \\
\text { holes, A }\end{array}$ & $\begin{array}{c}\left(D / D_{o}\right) \\
\mathrm{B}\end{array}$ & $\begin{array}{c}\left(S / D_{o}\right) \\
\mathrm{C}\end{array}$ & $\mathrm{P} / \mathrm{W}$ & $\mathrm{S} / \mathrm{N}$ & $\begin{array}{l}\text { Test } \\
\text { no. }\end{array}$ & $\begin{array}{c}\text { Shape of } \\
\text { holes, A }\end{array}$ & $\begin{array}{c}\left(D / D_{o}\right) \\
\mathrm{B}\end{array}$ & $\begin{array}{c}\left(S / D_{o}\right) \\
\mathrm{C}\end{array}$ & $\mathrm{P} / \mathrm{W}$ & $\mathrm{S} / \mathrm{N}$ \\
\hline 1 & Hex. & 1.7 & 1.5 & 168.2 & 44.52 & 15 & Sq. & 1.6 & 1.4 & 161.9 & 44.18 \\
2 & Cir. & 1.7 & 1.5 & 167.3 & 44.47 & 16 & Hex. & 1.5 & 1.4 & 166.1 & 44.41 \\
3 & Sq. & 1.7 & 1.5 & 157.3 & 43.93 & 17 & Cir. & 1.5 & 1.4 & 163.0 & 44.24 \\
4 & Hex. & 1.6 & 1.5 & 164.9 & 44.35 & 18 & Sq. & 1.5 & 1.4 & 158.2 & 43.98 \\
5 & Cir. & 1.6 & 1.5 & 165.0 & 44.35 & 19 & Hex. & 1.7 & 1.3 & 173.1 & 44.77 \\
6 & Sq. & 1.6 & 1.5 & 155.1 & 43.81 & 20 & Cir. & 1.7 & 1.3 & 172.9 & 44.76 \\
7 & Hex. & 1.5 & 1.5 & 160.4 & 44.10 & 21 & Sq. & 1.7 & 1.3 & 168.9 & 44.55 \\
8 & Cir. & 1.5 & 1.5 & 160.6 & 44.11 & 22 & Hex. & 1.6 & 1.3 & 171.1 & 44.67 \\
9 & Sq. & 1.5 & 1.5 & 149.0 & 43.46 & 23 & Cir. & 1.6 & 1.3 & 170.8 & 44.65 \\
10 & Hex. & 1.7 & 1.4 & 170.4 & 44.63 & 24 & Sq. & 1.6 & 1.3 & 164.9 & 44.35 \\
11 & Cir. & 1.7 & 1.4 & 170.1 & 44.62 & 25 & Hex. & 1.5 & 1.3 & 168.4 & 44.53 \\
12 & Sq. & 1.7 & 1.4 & 164.7 & 44.34 & 26 & Cir. & 1.5 & 1.3 & 166.5 & 44.43 \\
13 & Hex. & 1.6 & 1.4 & 168.2 & 44.52 & 27 & Sq. & 1.5 & 1.3 & 160.7 & 44.12 \\
14 & Cir. & 1.6 & 1.4 & 167.3 & 44.47 & & & & & & \\
\hline
\end{tabular}

From Table 7 and Figure 19, it can be seen that the optimum set of levels is (A1 B1 C3), which gives the best strength to weight ratio. The combination of the parameters is the hole with a hexagonal shape, $D / D_{o}=1.7$ and $S / D_{o}=1.3$. Delta column refers to the difference between the maximum and minimum level values. It showed that the shape of the holes has more effect on the buckling strength than the other parameters. ANOVA was employed to verify the results of Taguchi and confirming the more influential factor on the buckling strength. The significance of the test was $5 \%$. The null hypothesis was that the three factors have no worthy effects on buckling strength, and the alternate hypothesis was that the parameters have considerable effects. Table 8 contained the results of the ANOVA. By comparing the value of $F$ (F-static test) with the F- distribution table (with 5\% confidence) in reference [35], it was found that the null hypothesis is rejected, and the most influential factor is the shape of holes, and the low effect is the $D / D_{o}$. F- test result agrees with a percentage (P), where the $\mathrm{SH}$ has the highest contribution (38.95\%), and the lowest effect is the opening ratio $D / D_{o}$ $(23.42 \%)$.

Table 7. The analysis of mean results based on S/N.

\begin{tabular}{lcccccc}
\hline Symbol & Factor & Level1 & Level 2 & Level3 & Delta & Rank \\
\hline A & Shape & 44.5 & 44.45 & 44.08 & 0.42 & 1 \\
B & $D / D_{o}$ & 44.51 & 44.37 & 44.15 & 0.36 & 3 \\
C & $S / D_{o}$ & 44.12 & 44.38 & 44.53 & 0.41 & 2 \\
\hline
\end{tabular}




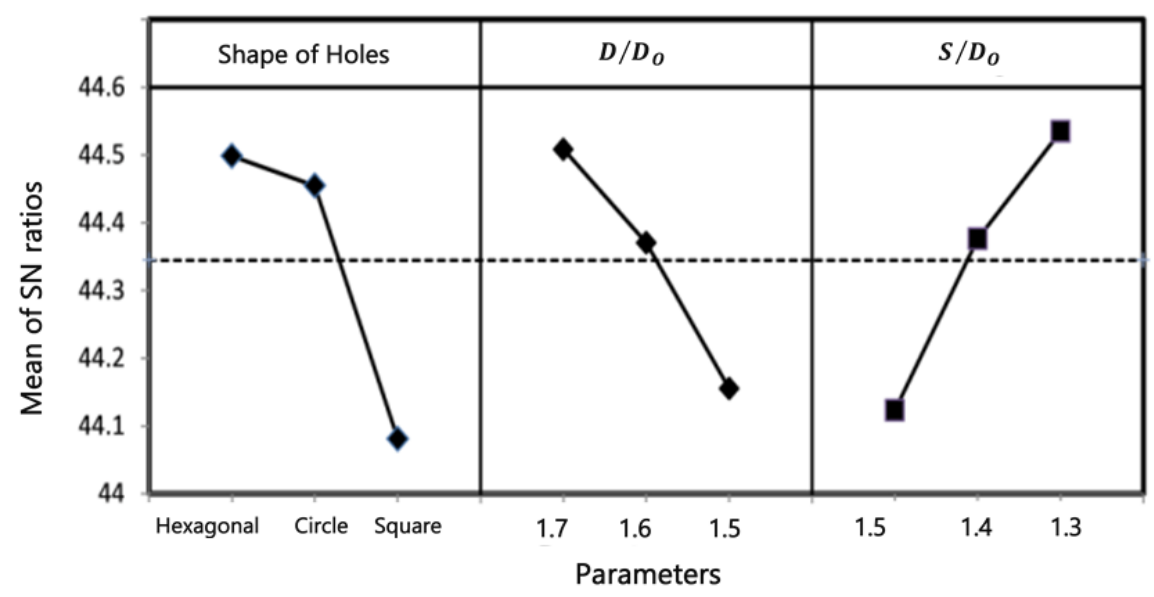

Figure 17. Main effect plot of $\mathrm{S} / \mathrm{N}$ ratios.

Table 8. The results of ANOVA.

\begin{tabular}{lccccc}
\hline Source & Sum sq. & d.o.f. & Mean sq. & F & P \% \\
\hline Shape & 0.9476 & 2 & 0.4738 & 68.67 & 38.95 \\
D/Do & 0.5697 & 2 & 0.2849 & 41.29 & 23.42 \\
S/Do & 0.7762 & 2 & 0.3881 & 56.24 & 31.91 \\
Error & 0.1393 & 20 & 0.0069 & & \\
Total & 2.4328 & 26 & & & \\
\hline
\end{tabular}

\section{CONCLUSION}

In the current study, a finite element method was implemented to study the buckling behaviour of a holed thin-walled lipped beam under a bending load. The finite element models were validated by experimental experiences. Three variables, namely; the spacing ratio of $S / D_{o}$, perforated ratio $\mathrm{D} / \mathrm{D}_{\mathrm{o}}$, and the shape of holes were designated to recognise the optimum combination set of them for the best critical load value. Taguchi and ANOVA methods were applied to analyse the outcomes of the finite element to specify the effect of the three parameters and their combinations. The results of these methods presented that the combination of factors that produces the best buckling strength value is the hole with a hexagonal shape, $\mathrm{D} / \mathrm{D}_{\mathrm{o}}=1.7$ and $\mathrm{S} / \mathrm{D}_{\mathrm{o}}=1.3$, and the shape of holes has more effect than the others on the buckling behaviour.

\section{ACKNOWLEDGEMENT}

Thanks and gratitude to the Department of Production Engineering and Metallurgy / the University of TechnologyBaghdad, for their cooperation to conduct the experimental tests in the strength of material labs.

\section{REFERENCES}

[1] N. W. Murray, Introduction to the theory of thin-walled structures. Oxford: Clarendon Press, 1986.

[2] G. J. White, R. H. Grzebieta, and N. W. Murray, "Maximum strength of square thin-walled sections subjected to combined loading of torsion and bending," Int J Impact Eng, vol. 13, no. 2, pp. 203-214, 1993, doi: 10.1016/0734-743X(93)90093-M.

[3] C. E. Javaroni and R. M. Goncalves, "Distortional buckling of simple lipped channel in bending," In 18th Int Spec Conf cold-formed Steel Struct, 2006, pp. 133-146.

[4] L. Zhang and G. S. Tong, "Elastic flexural-torsional buckling of thin-walled cantilevers," Thin-Walled Struct, vol. 46, pp. 2737, 2008, doi: 10.1016/j.tws.2007.08.011.

[5] J. Ye, I. Hajirasouliha, and J. Becque, "Experimental investigation of local-flexural interactive buckling of cold-formed steel channel columns," Thin-Walled Struct, vol. 125, no. July 2017, pp. 245-258, 2018, doi: 10.1016/j.tws.2018.01.020.

[6] Z. Kolakowski and J. Jankowski, "Interactive buckling of steel LC-beams under bending," Materials (Basel), vol. 12, no. 9, pp. 1-17, 2019, doi: 10.3390/ma12091440.

[7] M. Grenda and P. Paczos, "Experimental and numerical study of local stability of non-standard thin-walled channel beams," J Theor Appl Mech, vol. 57, no. 3, pp. 549-562, 2019, doi: 10.15632/jtam-pl/109601.

[8] C. D. Moen and B. W. Schafer, "Impact of holes on the elastic buckling of cold- formed steel columns," Int Spec Conf ColdFormed Steel Struct, pp. 269-283, 2006.

[9] C. D. Moen and B. W. Schafer, "Experiments on cold-formed steel columns with holes," Thin-Walled Struct, vol. 46, no. 10, pp. 1164-1182, 2008, doi: 10.1016/j.tws.2008.01.021.

[10] M. P. Kulatunga and M. Macdonald, "Investigation of cold-formed steel structural members with perforations of different arrangements subjected to compression loading," Thin-Walled Struct, vol. 67, pp. 78-87, 2013, doi: 10.1016/j.tws.2013.02.014.

[11] M. P. Kulatunga et al., "Load capacity of cold-formed column members of lipped channel cross-section with perforations subjected to compression loading - Part I: FE simulation and test results," Thin-Walled Struct, vol. 80, pp. 1-12, 2014, doi: 10.1016/j.tws.2014.02.017. 
[12] M. Macdonald and M. P. Kulatunga, "The effects of end conditions on the load capacity of cold- formed steel column members of lipped channel cross- section with perforations subjected to compression loading," 22nd Int Spec Conf Recent Res Dev Cold-Formed Steel Des Constr, pp. 129-142, 2014.

[13] M. Macdonald, M. Kulatunga, and M. Kotełko, "The effects of compression loading on perforated cold-formed thin-walled steel structural members of lipped-channel cross-section," AIP Conf Proc, vol. 2060, pp. 1-12, 2019, doi: 10.1063/1.5086138.

[14] L. F. Grilo et al., "Design procedure for the web-post buckling of steel cellular beams," J Constr Steel Res, vol. 148, pp. 525541, 2018, doi: 10.1016/j.jcsr.2018.06.020.

[15] F. P. V. Ferreira and C. H. Martins, "LRFD for Lateral-Torsional Buckling Resistance of Cellular Beams," Int J Civ Eng, vol. 18, no. 3, pp. 303-323, 2020, doi: 10.1007/s40999-019-00474-7.

[16] N. Degtyareva et al., "Local buckling strength and design of cold-formed steel beams with slotted perforations," Thin-Walled Struct, vol. 156, no. July, 2020, doi: 10.1016/j.tws.2020.106951.

[17] Khamlichi, "Effect of two interacting localised defects on the critical load for thin cylindrical shells under axial compression," Am J Eng Appl Sci, vol. 3, no. 2, pp. 464-469, 2010, doi: 10.3844/ajeassp.2010.464.469.

[18] C. Press et al., "Assessing the effect of two entering triangular initial geometric imperfections on the buckling strength of an axisymmetric shell subjected to uniform axial compression," Proc Elev Int Conf Comput Sructures Technol, pp. 1-11, 2012.

[19] J. C. Lin and K. Lee, "Optimisation of bending process parameters for seamless tubes using taguchi method and finite element method," Adv Mater Eng, vol. 2015, pp. 1-8, 2015, doi: 10.1155/2015/730640.

[20] R. Azadi and Y. Rostamiyan, "Experimental and analytical study of buckling strength of new quaternary hybrid nanocomposite using Taguchi method for optimisation," Constr Build Mater, vol. 88, pp. 212-224, 2015, doi: 10.1016/j.conbuildmat.2015.04.018.

[21] H. M. H. Al-Khafaji and H. M.AL-khafaji, "Best level of parameters for a critical buckling load for circular thin- walled structure subjected to bending Hussein," Al-Khwarizmi Eng J, vol. 13, no. 4, pp. 12-21, 2017, doi: 10.22153/kej.2017.07.003.

[22] D. S. Khazaal, H. M. AL-khafaji, and I. A. Abdulsahib, "Buckling behavior of aluminum alloy thin-walled beam with holes under compression loading," J Eng, vol. 26, no. 9, pp. 137-154, 2020, doi: 10.31026/j.eng.2020.09.15.

[23] T. V. Galambos, Guide To Stability Design Criteria for Metal Structures, 5th ed. Canada: John Wiley \& Sons, Inc., 1998.

[24] Y. V. Narayana et al., "Nonlinear buckling and post-buckling analysis of imperfect cylindrical shells subjected to axial compressive load," J Struct Eng, vol. 42, no. 2, pp. 114-121, 2015.

[25] S. Deshpande, "Buckling and post bukcling of structural components," M.S. thesis, The University of Texas at Arlington, USA, 2010.

[26] M. S. Phadke, “Quality engineering using robust design,” New Jersey: P T R Pentice Hall, Englewood Cliffs, 1989.

[27] Rupert G. Miller, "Beyond ANOVA, basics of applied statistics.” John Wiley \& Sons, Inc., Canada, 1986.

[28] ASTM, "Standard test methods of tension testing wrought and cast aluminum- and magnesium-alloy products [Meteric]," in Designation: B 557M - 94 Metric, vol. 02, American Society for Testing and Materials, 2003, pp. 1-19.

[29] E. C. for Standardization, "Eurocode 3: Design of steel structures Part 1-3: General rules - Supplementary rules for coldformed members and sheeting," in Design of Structural Elements, Brussels, 2009.

[30] "Steelwork Design Guide to BS 5950-1: 2000," $7^{\text {th }}$ ed., vol. 1, London: Jointly published by: The Steel Construction Institute and The British Constructional Steelwork Association Limited, 2007.

[31] E. Madenci and I. Guven, The finite element method and applications in engineering using ANSYS. Springer US, 2006.

[32] M. U. Hosain and W. G. Speirs, "Experiments on castellated steel beams," We;domg Kpirma; , no. August, pp. 329-342, 1973.

[33] F. P. V. Ferreira, A. Rossi, and C. H. Martins, "Lateral-torsional buckling of cellular beams according to the possible updating of EC3," J Constr Steel Res, vol. 153, pp. 222-242, 2019, doi: 10.1016/j.jcsr.2018.10.011.

[34] R. A. Bhat and L. M. Gupta, "Moment-gradient factor for perforated cellular steel beams under lateral torsional buckling," Arab J Sci Eng, vol. 45, no. 10, pp. 8727-8743, 2020, doi: 10.1007/s13369-020-04836-5.

[35] D. C. Montgomery, Design and Analysis of Experiments, Eighth Edi., no. Fifth edition. John Wiley \& Sons, Inc., 2013. 